DOI: $10.35218 /$ armca.2020.1.11

\title{
About the world of magical symbols, using the language of contemporary world
}

\section{Adrian Stoleriu}

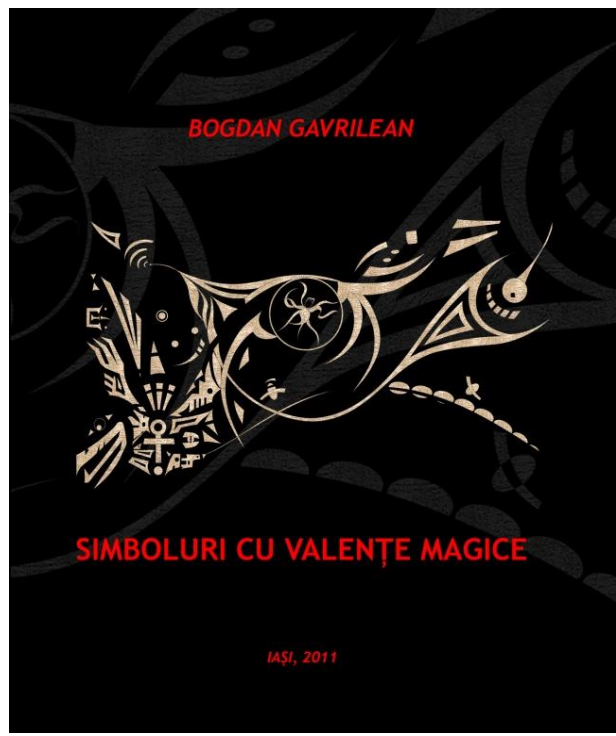

Bogdan Gavrilean, Simboluri cu valente magice [Symbols with a Magical Value], "Artes" Publishing House, Iași, 2011

What is the place occupied today by the interpretations dedicated to the world of symbols, after having had so many studies on this topic in the past decades marked by opinions, beliefs, theoretical verdicts and specific interpretations? Given the large bibliography dedicated to this important area of research, the emergence of a new work having as topic the symbol and its interpretation is regarded in a complex manner, both from the perspective of scientific norms and rigors - which ask for the tribute of recognizing already established theories and studies in this field-, and from the point of view of an eternal curiosity, of a continuous need of discovering new meanings, reasons and valencies for what the symbol represents today. This endeavour is also justified by the fact that -in the present article- we have referred to a visual artist, equally interested in theoretical research, but also practical ones, specific to the world of art. The answer to the question we have just launched is maybe already known, the perennity of symbols determines - from now on - the start of a new and challenging research.

It is the case of the present paper, suggestively entitled Symbols with magical valencies, created by Bogdan Gavrilean, a visual artist and member of the academic staff of the Faculty of Visual Arts and Design from the National University of Arts "George Enescu" from Iași. Based on the admitted "artistic obsession" of the author, having deep roots, ever since he was doing research for his $\mathrm{PhD}$ paper, the present study is the expression of 
his interest for "the fascinating world of symbols, [an interest which] has its origin in ideatic quests and technical-artistic experimesnts which have lasted for a long time, focused on the direction of discovering a personal way of expressing individual sensitivity" (p.15). The large research on symbols starts with Bogdan Gavrilean's declaration of honesty, proposing a complex analysis of different hypostases and interpretations of the symbol, by underlining its connections to the field of myths, magical rituals and religious representations.

The work is structured in three major chapters (I. Signs and symbols, II. The human dimension of creation and III. Symbols with magical valencies in personal artistic creation), each of them being divided in a rich structure of subchapters, treating different aspects, specific to the theory and artistic practice inspired by the world of symbols. The first of these major chapters debates on a complex topic, the purpose is to create a series of conceptual delineations regarding the signs, the symbols, the sciences and the theories involved in their study. The author presents a large typology of symbols, divided in sacred, magical and planetary symbols, in elements and manifestations of nature, in expressions of the human being, in geometrical symbols, in the symbolism of colours and last, but not least, the symbolism of metals.

An interesting vision, specific to this paper is about the expressive force of symbols, thus underlining the fundamental role played by perception, reason, sensibility and intuition for deciphering their plurivalence. The interpretation of symbols vacillates nowadays between "potentiality and pervertion", between "incantations and manipulation", the two poles of analysis signaled by the author. Once the transition from traditional societies - known for their deeply spiritual vision about the world and existence -, to modern ones was made, secularized or even desacralized of the present, the symbol passes in its turn through a similar process of transformation, losing its originar meanings in many cases, thus acquiring new, unexpected new ones or emptied of their primordial essence. The symbol thus becomes a bridge between past and present, reactivating the spiritual universes of longforgotten worlds or itself becoming an expression of the way in which the contemporary world connects to these realities.

The second part of the paper is dedicated to the exploitation of some socio-cultural premises, by underlining the influence factors of the process of art spreading or the spreading of new conceptual perspectives due to "the death of art" or the innovative artistic shock which tends to attract more and more nowadays artists. The problematics of the genesis of the work of art, of the creative process and the impossibility of its rational translation into words become topics of an interesting questionning on the primordial factors which constitute the basis of the mechanisms of artistic creation. By oscillating between the argument of reason and sensitivity, the author reaches the 
conclusion that "we cannot talk of a rational vision of the act of creation, if there is no intention of the artist in the first place, followed by a practical finality of the act of creation. This intention can sometimes be obvious, but in other situations, its deciphering can be difficult regarding the way of artistic or compositional expression of the artist, especially when one uses nonconventional techniques or methods."( $\mathrm{p} .127)$

Therefore, this is the reason why the author stops to analyze the intentional or non-intentional character of art, introducing new categories in this already complicated theorem of artistic creation such as the ludic or the pathological. In the same manner, the author courageously launches himself into an analysis which is specific to theoreticians, argumentedly investigating a series of perpetual aspects of criticism, such as the interpretation of a work of art and the crisis of the artistic endeavour generated by the collation of the author's intention to the ones of the public. In his complicated attempt of reaching some conclusions, Bogdan Gavrilean signals in his turn this interesting intentional contrast, by asking himself: "Which of these intentions has thus priority, the artist's or the one of the interpreter of the artist's creation?". (p.135) The last part of this chapter (no.2) is focused on underlining the role that the subjectivity of the artist plays in accomplishing one's creation, defined as an enigma which will permanently attract the honest interest of artists and theoreticians.

The third and last part of the paper is the one dedicated to the representation of symbols with magical valences in personal artistic creation, this chapter starts with a series of questions regarding the meanings and implications of this concept on the human psyche, questionning by this the need of the human being, and in particular of the artist, of symbols.

Obviously, the passing through his own filter of thinking and feeling of the theories about symbols makes this part of his paper be the most original one, thus enjoying a rich imagistic material, of very good quality, extracted from the portfolio of personal creation. This is the part which underlines, in the clearest way, the double quality of this author, quality owned by the author while creating this book, the one of theoretician, respectively the one of visual artist, of practitioner directly involved in the process of artistic creation and in transposing in images the themes and subjects which preoccupy him, among which the symbols which certainly occupy a one of the top ranking places.

If we simply enumerate the titles of the papers that he describes and illustrates - Germinație [Germination], Ichthys [The Fish], Nucleu [Nucleous], Principiul uniunii [The Principle of Union], Ritual de trecere [The Ritual of Passing], Căderea ingerului din Rai [The Fall of the Angel from Heaven], Genesis, Alfa şi Omega [Alpha and Omega] - we believe it is a convincing pleading for the importance of sacred symbols for the artistic creation in general, but also for the personal one, in particular. 
Thus structured, the 248 pages of the book Symbols with Magical Valences, published by Artes Publishing House in 2011 (but only recently printed, after a long process of germination), invites the reader to a large and challenging theoretical periplus, underlining the value of symbols in the development of culture and human spirituality. In this respect, Bogdan Gavrilean - the artist, researcher and academic professor - has as objective to fully take advantage of the "space" of his book, offering the proof of a special generosity towards his readers that he charms up to the last page with information, images, quotations, opinions or ideas meant to argument his discourse and its deep essence: "Have a look and see everything there is on the face of the Earth. You will see, maybe, fortresses without walls, without laws, you will meet peoples that do not know how to write and use money, but no one has ever met a nation without God (Plutarh)". (p.248) 